\title{
Assessment of the last-in-first out principle of access for managing the connection of distributed wind generators
}

\author{
D. Danzerl*, S. Gill ', I. Kockar ${ }^{\dagger}$, O. Anaya-Lara ${ }^{\dagger}$ \\ *Institute of Energy and Envrironment, Wind Energy CDT, University of Strathclyde, UK. \\ daniel.danzerl@strath.ac.uk \\ ${ }^{+}$Institute of Energy and Environment, University of Strathclyde, UK \\ simon.gill@strath.ac.uk, ivana.kockar@strath.ac.uk,olimpo.anaya-lara@strath.ac.uk
}

\begin{abstract}
Recent projects in the UK have investigated different connection arrangements for managing distributed wind generators to maintain thermal limits and a number of principle of access for generators to the limited distribution network capacity have been investigated. However, principle of access to manage voltage limits have not received as much attention. This study aims to evaluate the current practice for connecting 'non-firm' distributed wind generators under both voltage and thermal constraint conditions. It addresses the issue by developing a representative model of a UK $11 \mathrm{kV}$ radial distribution feeder comprising a mix of urban and rural sections using time-step optimal power flow simulations. The results indicated that when the principle is applied under both network constraint conditions, it can lead to inefficient use of network capacities and reduced renewable energy yields.
\end{abstract}

Keywords: Principles of Access (POA), Generation Curtailment, Distributed Wind Generation, Active Network Management (ANM), Optimal Power Flow (OPF)

\section{Introduction}

Distribution network operators (DNOs) are seeking smarter commercial arrangement to connect distributed renewable generation in a timely and cost effective manner [1]. On distribution networks in Great Britain (GB), increased penetration of renewable generation connections is presenting a number of challenges and uncertainties to network operation and security. These challenges including voltage fluctuations, thermal capacity congestions, and reverse power flows [2] are made more challenging by the stochastic nature of the renewable resources' power output. These factors imply that network constraints can, if not properly managed, significantly limit the capacity of distributed generation allowed to connect. In turn this limits the economic benefit of renewable generation [3]. The advent of active network management (ANM) techniques provides smarter alternative solutions to distribution management to otherwise costly and time consuming network upgrades [4].

Under ANM schemes, where generation can exceed the network capacity to access and export power, a connection principle of access (POA) is required. The prevailing POA in GB distribution networks is a last-in-first out (LIFO) arrangement [5]-[6]. The method requires the most recently connected DG unit to curtail its active power output first during a network constraint, if further curtailment is required the second generator reduces its output. LIFO defines a priority stack that governs generator access to available network capacity in real-time and specifies the manner in which to curtail generators. This arrangement is seen as simple and straight forward to implement and understand as it fixes network access rights for each generator at initial stages of DG investments (later connecting generators do not impact on the level of curtailment experiences by existing generators). However, LIFO is not the most economically efficient and attractive option for connecting DGs [7]-[8].

Recent ANM schemes such as the Orkney ANM scheme (in the North of Scotland) are enhancing network hosting capacities by implementing ANM to facilitate increased DG connections and grid access [9]. Distributed generators wishing to connect under ANM schemes to the limited network are offered 'non-firm' contracts which means, they can be instructed to curtail their output during a constraint event. By offering non-firm connections, the DGs are able to access the network and significant cost associated with network capacity upgrades can be minimised, deferred or avoided. An assessment undertaken by [10] of the Orkney ANM scheme indicate that loss of revenue through controlled curtailment result in the least expensive option to network management when compared with traditional reinforcement.

Whilst LIFO has proved success for thermally constrained networks, there is an increased need to develop new POA regimes for ANM schemes that enhances DG network access in an economically attractive manner whilst managing voltage constraints and further investigation of greater efficiencies at thermal levels [11]-[12]. New strategies should ensure better utilisation of network asset capacities in order to make ANM schemes competitive and provide the confidence for operators and developers. This will be coupled to a comprehensive revision of the current regulatory framework and the distribution codes that governs the connection of distributed wind generators (DWG).

Whilst the compromises of LIFO have been deemed acceptable for thermal constrained networks, the same is not true for networks where voltage constraints are binding. With a thermal constraint, to first order (with a small error due to losses), the location of a generator behind a constraint does not change its impact on that constraint; the same is not true for a voltage 
constraint where the location of the generator is a significant factor. This paper aims to show the impact of priority order of a LIFO scheme when applied to connect non-firm wind generators under both voltage and thermal constraint conditions. It presents a detailed case study assessment and concludes that, LIFO leads to the risk of significantly underutilising the network capacities and reduces economic benefit of wind capacity integration into distribution networks.

\section{Last-in-first out (LIFO) Principle of Access}

The commercial framework for allocating limited network capacity in ANM schemes has been characterised by [13]. Prior work undertaken by [14] provide an initial assessment of the POA options against set criteria which considered the technical, commercial and regulatory strengths of each approach. A number of POA options have also been studied by [3] and [7] where the authors highlighted some of the advantages and disadvantages of each option. Similarly, UK Power Networks, a GB DNO, have also carried out analysis of alternative POA in [15] as part of their Flexible Plug and Play project. The authors reported LIFO as simple to implement but chose to test Pro-Rata curtailment as the basis for a new commercial approach to drive greater connections of renewable generators. In [16] LIFO and Market Based approaches are seen as the most feasible solutions to curtailment in ANM schemes.

The current LIFO methodology involves a successive scheduling of curtailment behind the non-firm generators (NFGs) when the network lines are congested, with the highest amount of curtailment suffered by the last generator to connect to the network. The energy yields from the firm generators already connected are unaffected by the connection of subsequent non-firm DGs [17]. LIFO suffers from a number of drawbacks: it is not the most efficient and economical way of managing the network and when applied to voltage constraint situations does not take account of generator location when defining priorities. These concerns are listed below;

- LIFO does not fully maximise capacities of economically viable wind generators.

- LIFO underutilises distribution network capacities resulting in reduced generation levels.

- In the event of thermal constraints, all DGs are approximately equal contributors to the constraint; however, this condition is untrue for voltage constraint situation.

- LIFO is particularly inefficient in managing voltage constraints on the network as voltage rise issues is a local area problem.

- Wind generators located at weaker parts of the network will impact on voltage levels significantly more than in stronger locations and as such may suffer higher levels of unnecessary curtailments.

With an increase in the number and capacity of connected DG units, the LIFO approach may hinder some investments in DGs as newly connected DGs may be faced with limited network access as a result of frequent interruptible connections. This may be seen as barrier to fulfilling obligations of European Union's 2020 renewable targets of generating electricity from low carbon technologies. This indicate that there is a growing need to develop new LIFO regimes that optimises network assets and accelerates distributed wind generation connections. In [16], the authors acknowledged that POA for connecting DG units is an evolving process. In [17] the authors investigated other forms of connection principles with findings showing improved network access and subsequent energy yields.

\section{Optimal Power Flow Formulation}

Previous work reported by the authors in [5] involves an OPFLIFO formulation in which the cost curves of each DG unit is modified and tuned to reflect the connection order, with the highest cost of generation associated to the last DG unit to connect. A similar 'pseudo' cost approach to define the preferential curtailment of different generation technologies have also been reported by [18] where arbitrary cost values are assigned to the DGs to prioritise their dispatch.

In this paper a new OPF-LIFO methodology is modelled and implemented for a network with both network voltage and thermal constraints. The proposed methodology is part of the major contributions of this paper. The technique effectively uses AC-OPF to schedule generators one at a time using a multi-stage process. Effetely it sets and fixes the outputs of the highest priority generator with all lower-priority generators removed, then fixes that generator output for all further stages. The case study utilises the standard ACOPF formulation [19], [20] at each time-step with an overall objective to maximise renewable generation levels at minimum costs and is given as follows:

$$
\min C=\sum_{i=1}^{N G} \alpha_{i}+\beta_{i}\left(P_{G i}\right)+\gamma_{i}\left(P_{G i}\right)^{2}
$$

Equation (1) represent the quadratic objective function of generator unit $i$ where; $C$ is the total cost of generation, $\alpha_{i}, \beta_{i}, \gamma_{i}$ are the cost coefficients, with active power output $P_{G i}$. The optimization formulation assigns very low cost values to all the DG units and very high values to injection of power at the swing bus, which represents imports from an external grid. Equation (1) is subject to the following equality and inequality constraints;

a. The power balance equation given in (2) and (3) which includes constraints on nodal real and reactive power balance:

$$
\begin{gathered}
P_{G i}-P_{D i}-\sum_{i=1}^{n}\left|Y_{i j} V_{j} V_{i}\right| \cos \left(\theta_{i j}+\delta_{j}-\delta_{i}\right)=0 \\
Q_{G i}-Q_{D i}+\sum_{i=1}^{n}\left|Y_{i j} V_{j} V_{i}\right| \sin \left(\theta_{i j}+\delta_{j}-\delta_{i}\right)=0
\end{gathered}
$$

where; $Q_{G i}$ represents generator unit reactive power output. $P_{D i}$ and $Q_{D i}$ are the system's real and reactive demands at the $i^{\text {th }}$ bus, while $V_{i}, V_{j}, \delta_{i}, \delta_{j}$ are the bus voltage magnitudes and angles at bus $i$ and $j$. 
b. Generation limits of the distributed wind generators

$$
\begin{gathered}
P_{G(\text { avail })}^{\min } \leq P_{G} \leq P_{G(\text { avail })}^{\max } \\
Q_{G(\text { avail })}^{\min } \leq Q_{G} \leq Q_{G(\text { avail })}^{\max }
\end{gathered}
$$

where; $P_{G \text { (avail); }}^{\max }$ and $P_{G \text { (avial) }}^{\min }$ are the upper and lower limits of the DGs available active power generation at any time-step and $Q_{G \text { (avail) }}^{\min }$ and $Q_{G \text { (avail) }}^{\max }$ are the upper and lower limits of available reactive power generation at any time-step. The DGs are assumed to be operating at unity power factor, hence zero reactive power contributions in this case.

c. The voltage limits at each bus where it is assumed that the maximum and minimum limits remain fixed across the optimization horizon.

$$
V_{i}^{\min } \leq V_{i} \leq V_{i}^{\max }
$$

d. Thermal line limits that constrains the apparent power flows along each line.

$$
\left|S_{i j}\right| \leq S_{i j}^{\max }
$$

where; $V_{i}^{\min }$ and $V_{i}^{\max }$ are the upper and lower bus voltage limits, while $S_{i j,(\max )}$ is the apparent power thermal limits of the lines and cables.

\section{Case - Study}

The case study network is presented in Fig. 1. The model is deployed in Matpower [21] and simulation studies are carried over a year period. The model comprises a mix of urban sections consisting of underground cables with high $\mathrm{R} / \mathrm{X}$ ratios and rural sections consisting of overhead lines with lower $\mathrm{R} / \mathrm{X}$ ratios. The primary substation is linked to a $33 \mathrm{kV}$ distribution system represented as a source of real and reactive power and operated at fixed voltage, with the remaining nodes representing secondary substations where the voltages are stepped down to $400 \mathrm{~V}$ for customer connections. Generator C (1MW)

\section{Urban section with underground cables $(4.3 \mathrm{~km})$ \\ ......... Rural section with overhead lines (13.2km)}
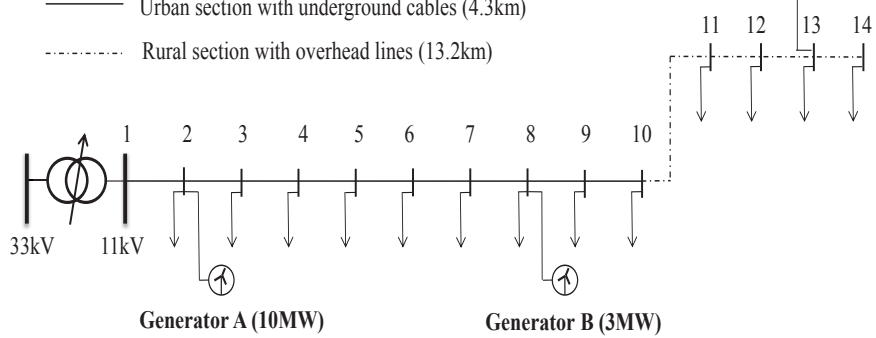

Fig. 1. $11 \mathrm{kV}$ radial distribution feeder

Fig. 2. shows a two-week sample of the half hourly time series of active demand used in the study which is taken from a real GB distribution network. The use of historic wind resources time-series, such as normalised output of a nearby wind farm is used to estimate potential generations. Fig. 3. shows a two- week sample of normalised wind generation profiles. Three DWGs of varied sizes are scaled from the normalised wind profile and connected at bus 2, bus 8 and bus 13. The operation conditions adopted for the case study sets and fixes voltage at the primary at $11.20 \mathrm{kV}$ and applies an upper voltage limits of $11.25 \mathrm{kV}$ and a lower voltage limits of $10.75 \mathrm{kV}$ at each secondary bus. The long-term thermal limits of the cables and overhead lines are set at 4.88MVA and 6.57MVA respectively as additional constraint on the network.

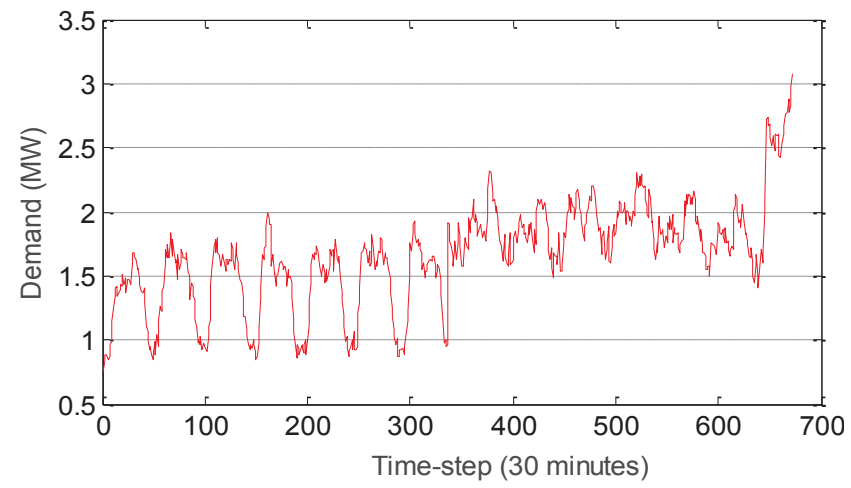

Fig. 2. Active demand profile (2-weeks)

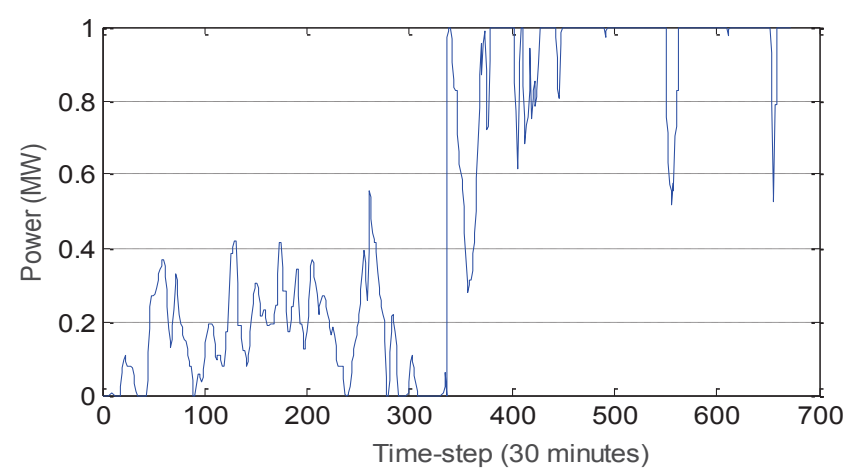

Fig. 3. Normalised wind generation profile (2-weeks)

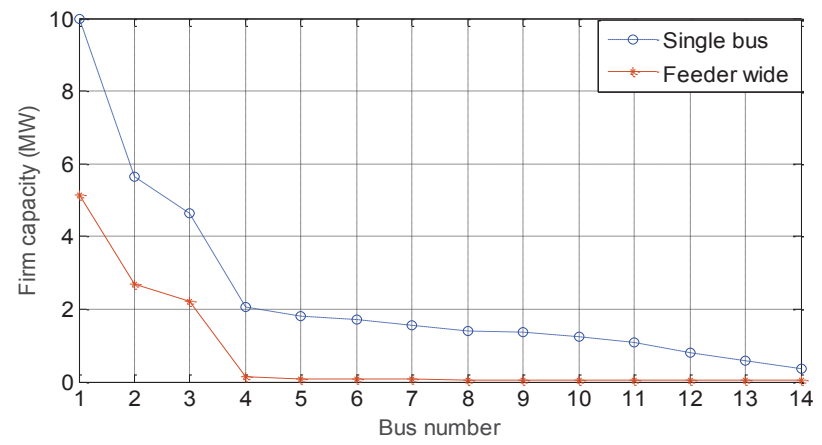

Fig. 4. Firm capacity profile

Initially, two estimates of firm generation capacity for each bus are made: (a) assuming no DG elsewhere on the feeder; and (b) by maximising firm capacity across the feeder. This was calculated accomplished using minimum demand condition. Fig. 4, shows both single-bus and feeder-wide firm capacities. It is observed that the DG generation capacities under voltage constraint conditions are significantly influenced by neighbouring generators and existing configurations on the network. 


\section{Results}

To identify the impact of LIFO priority order on curtailment of non-firm DWGs, six scenarios for the connection of the nonfirm generators under both network voltage and thermal constraints have been investigated. The sharing of limited network capacities is implemented by alternating the priority orders for which the DWGs connects and is summarised in Table 1. Each scenario provides an assessment of the level of curtailment needed to maintain the network limits and subsequent renewable energy yields of the generators.

Table 1 Summary of LIFO principle of access

\begin{tabular}{ccccc}
\hline Scenario & $\begin{array}{c}\text { High } \\
\text { priority }\end{array}$ & $\begin{array}{c}\text { Medium } \\
\text { priority }\end{array}$ & $\begin{array}{c}\text { Low } \\
\text { priority }\end{array}$ & $\begin{array}{c}\text { POA } \\
\text { rule }\end{array}$ \\
\hline 1 & Gen A & Gen B & Gen C & LIFO 1 \\
2 & Gen A & Gen C & Gen B & LIFO 2 \\
3 & Gen B & Gen A & Gen C & LIFO 3 \\
4 & Gen B & Gen C & Gen A & LIFO 4 \\
5 & Gen C & Gen A & Gen B & LIFO 5 \\
6 & Gen C & Gen B & Gen A & LIFO 6 \\
\hline
\end{tabular}

A sample of the scenarios and corresponding results obtained are illustrated below:

\section{A. Scenario 1}

\section{Gen A - Gen B - Gen C}

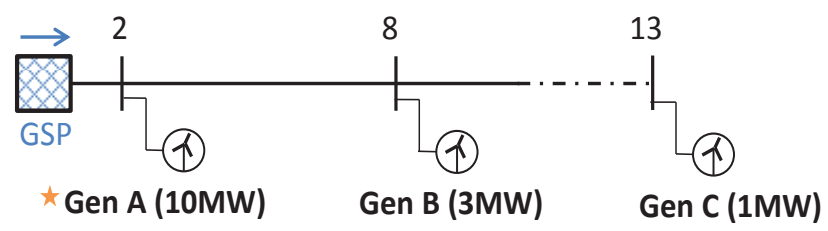

Fig. 5. Principle of access (LIFO 1)

Table 2 Summary of results at LIFO 1 arrangement

\begin{tabular}{lcccc}
\hline Generator & Gen A & Gen B & Gen C & Total \\
\hline Rated power (MW) & 10.0 & 3.0 & 1.0 & 14.0 \\
Available energy (GWh) & 39.43 & 11.83 & 3.94 & 55.20 \\
Generated energy (GWh) & 31.95 & 3.30 & 0.83 & 36.07 \\
Curtailed energy (GWh) & 7.48 & 8.53 & 3.12 & 19.13 \\
Generation (\%) & 81.03 & 27.86 & 20.96 & 65.35 \\
Curtailment (\%) & 18.97 & 72.14 & 79.04 & 34.65 \\
\hline
\end{tabular}

B. Scenario 3

\section{Gen B - Gen A - Gen C}

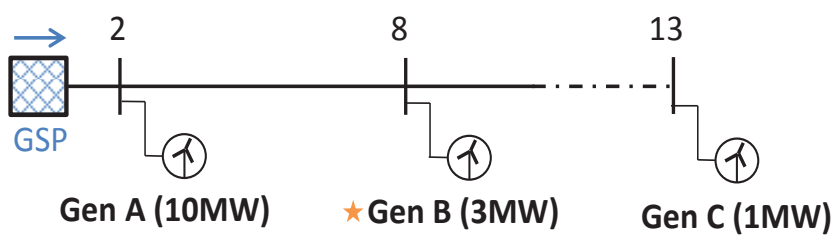

Fig. 6. Principle of access (LIFO 3)
Table 3 Summary of results at LIFO 3 arrangement

\begin{tabular}{lllll}
\hline Generator & Gen B & Gen A & Gen C & Total \\
\hline Rated power (MW) & 3.0 & 10.0 & 1.0 & 14.0 \\
Available energy (GWh) & 11.83 & 39.43 & 3.94 & 55.20 \\
Generated energy (GWh) & 10.34 & 12.76 & 0.82 & 23.92 \\
Curtailed energy (GWh) & 1.49 & 26.67 & 3.12 & 31.28 \\
Generation (\%) & 87.40 & 32.36 & 20.81 & 43.33 \\
Curtailment (\%) & 12.60 & 67.64 & 79.19 & 56.67 \\
\hline
\end{tabular}

\section{Scenario 6}

Gen C - Gen B - Gen A

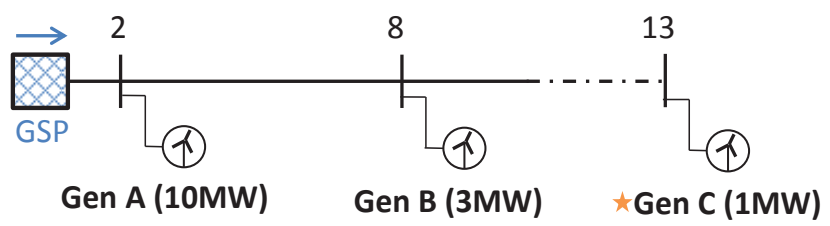

Fig. 7. Principle of access (LIFO 6)

Table 4 Summary of results at LIFO 6 arrangement

\begin{tabular}{lllll}
\hline Generator & Gen C & Gen B & Gen A & Total \\
\hline Rated power (MW) & 1.0 & 10.0 & 3.0 & 14.0 \\
Available energy (GWh) & 3.94 & 11.83 & 39.43 & 55.20 \\
Generated energy (GWh) & 3.85 & 5.30 & 8.77 & 17.92 \\
Curtailed energy (GWh) & 0.09 & 6.53 & 30.66 & 37.28 \\
Generation (\%) & 97.72 & 44.80 & 22.24 & 32.46 \\
Curtailment (\%) & 2.28 & 55.20 & 77.76 & 67.54 \\
\hline
\end{tabular}

\section{Discussion}

Fig. 8. illustrates a flow chart of the new OPF-LIFO algorithm implemented in the study. The multi-stage optimization assesses available online network capacities and determines maximum generation levels that can be injected onto the constrained network. It does not depend on fine tuning of generator prices and can hence be implemented without prior knowledge of generator real market price values. In this study, all DG units are assumed to be operating at the same cost values. The proposed OPF-LIFO algorithm can be applied in the methods implemented in [4] and [17] for connecting the DGs and prioritising their dispatch.

Voltage constraint conditions applied to manage the DWG connections under LIFO presents a host of complex challenges to the network. With the overall objective to maximise renewable generation levels, inappropriate choice of LIFO arrangement can result in higher amount of generation curtailment and may result in lower energy yields. Fig. 9, presents a detailed performance (in terms of the amount of renewable energy yields) of the individual DWG units under each LIFO arrangement over the year. It can be observed that generator $\mathrm{A}$ is highly favoured in almost all the LIFO arrangements due to its strong location on the network. Generator B placed in the middle section of the network is 
medium favoured, generator $\mathrm{C}$ located in the weaker section of the network being the least favoured.

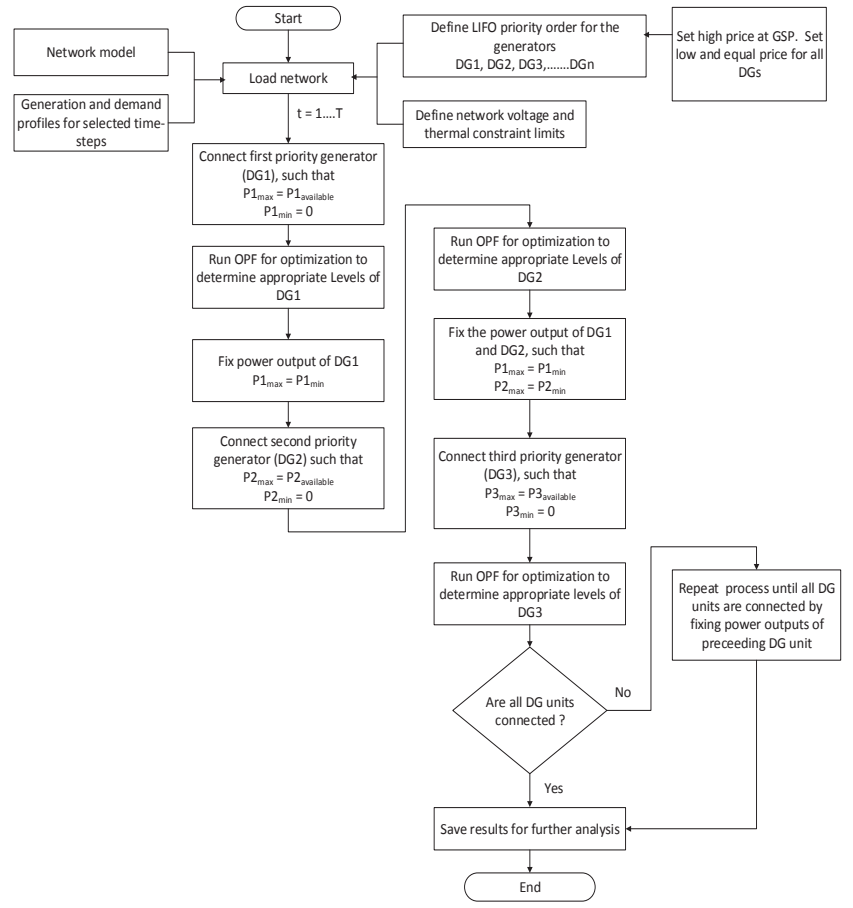

Fig. 8. New OPF-LIFO flow chart

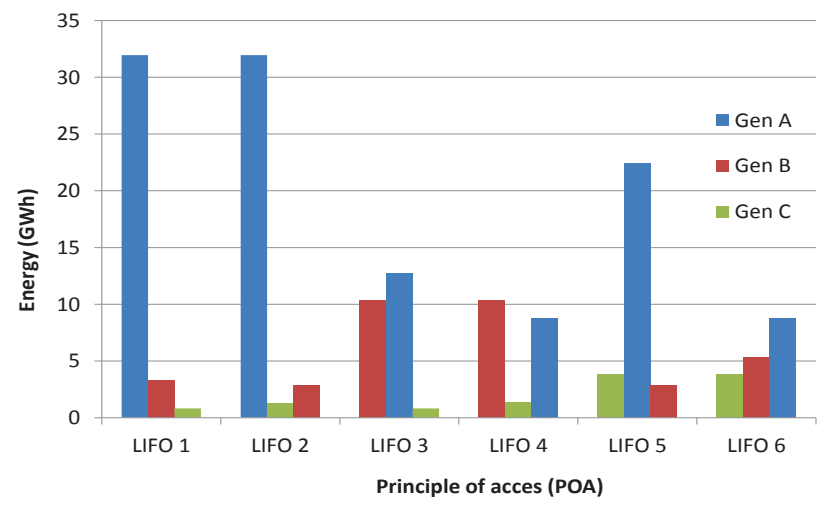

Fig. 9. Performance of DG units under LIFO

Fig. 10, illustrates the total renewable energy generated and curtailed under each LIFO arrangement when compared to the total energy available over the year period.

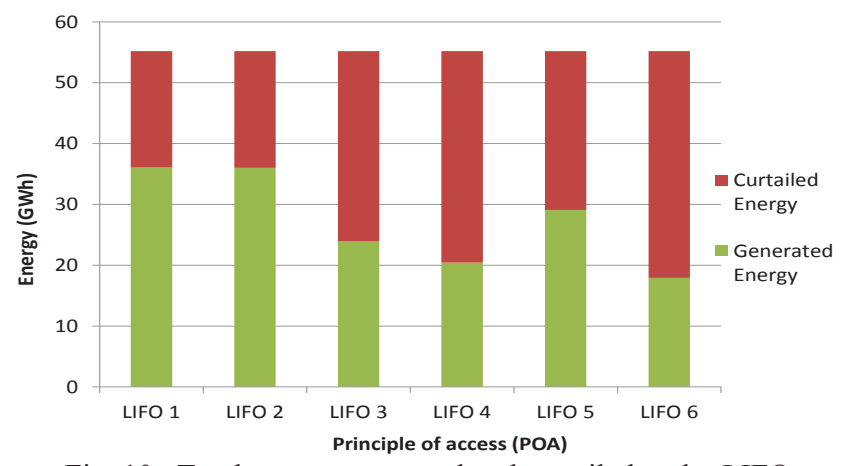

Fig. 10. Total energy generated and curtailed under LIFO
From Fig. 10, it can be observed that, LIFO 1 and LIFO 2 arrangements yielded the highest generation levels when compared with the rest. LIFO 6 yielded the least amount of generation, with the generators subjected to high levels of curtailments. In both LIFO 1 and LIFO 2 arrangements, greater generation levels were realised due to high priority given to generator A which is located at the strong section of the network. High priority given to generators at this location has very low impact on voltage rise, hence reduced curtailments allowing greater penetration for other connected generators. In the case of LIFO 6, the least amount of generation is realised due to high priority given to generator $\mathrm{C}$ which is located at the weak section of the network. Any generator connected at this location will significantly impact on voltage rise, causing severe curtailment of all connected generators. Also a medium priority assigned to generator B which is smaller in size and further away from the primary substation results in reduced energy yields. Fig. 11 shows the highest voltage profiles seen under LIFO 1 and LIFO 6 arrangements for comparison. The study is undertaken from the same time-step at which the voltage magnitudes at bus 2 , bus 8 and bus 13 reaches the maximum upper constraint limits.

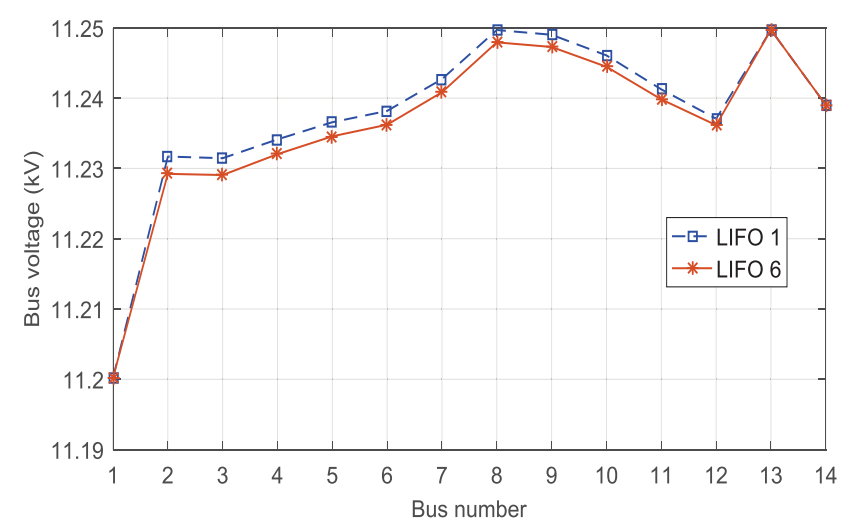

Fig. 11. Voltage profiles (single time-step)

LIFO 1 can be seen to have a higher voltage along the majority of the feeder, with two point at which the voltage reaches the upper limits namely bus 8 and bus 13. By contrast, LIFO 6 has only one point at which the voltage is constrained. A summary of the generator outputs and curtailments are shown in Table 5.

Table 5 Summary of generation results

\begin{tabular}{|c|c|c|c|c|c|c|c|c|}
\hline POA & \multicolumn{4}{|c|}{ LIFO 1} & \multicolumn{4}{|c|}{ LIFO 6} \\
\hline Generator & A & B & $\mathrm{C}$ & Total & $\mathrm{C}$ & B & $\mathrm{A}$ & Total \\
\hline $\begin{array}{l}\text { Available } \\
\text { power(MW) }\end{array}$ & 4.31 & 1.29 & 0.43 & 6.04 & 0.43 & 1.29 & 4.31 & 6.04 \\
\hline $\begin{array}{l}\text { Generated } \\
\text { power (MW) }\end{array}$ & 4.31 & 1.29 & 0.42 & 6.02 & 0.43 & 1.29 & 3.98 & 5.71 \\
\hline $\begin{array}{l}\text { Curtailed } \\
\text { power (MW) }\end{array}$ & 0 & 0 & 0.01 & 0.01 & 0 & 0 & 0.33 & 0.33 \\
\hline Generation (\%) & 100 & 100 & 97.15 & 99.80 & 100 & 100 & 92.35 & 94.53 \\
\hline Curtailment (\%) & 0 & 0 & 2.85 & 0.20 & 0 & 0 & 7.65 & 5.47 \\
\hline
\end{tabular}

Fig. 12. represents the thermal profiles along the underground cables and overhead lines when thermal constraints are considered under LIFO 1 and LIFO 6 arrangement at the same 
time-step at which the voltage magnitudes at bus 2 , bus 8 and bus 13 reaches the maximum upper constraint limits.

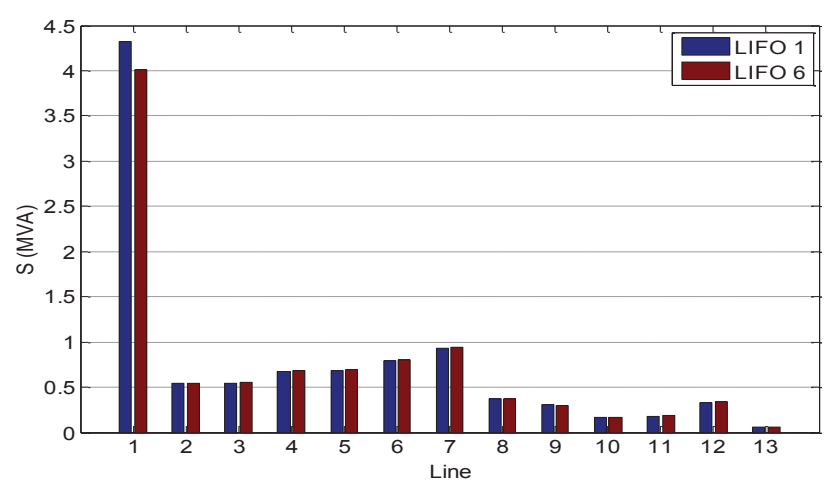

Fig. 12. Thermal profile

\section{Conclusion}

This paper has presented a detailed case study assessment of the LIFO principle of access philosophy for connecting DWGs under network voltage and thermal constraint conditions. The study showed that, although LIFO has proven to be successful in current UK ANM schemes when applied under voltage constrained situations it can lead to a reduction in renewable energy levels. The study revealed that under the LIFO scheme, generators located at weaker sections of the network may suffer severe curtailment due to their impact on local voltage rise issues than generators located at stronger sections of the network. Furthermore, applying LIFO POA rule that gives high priority to generators located at weak sections of the network can impose significantly, greater curtailment on other generators regardless of their own local network strength and as a result may lead to reduced energy yields, highlighting a major drawback to this rule. Key lessons derived from this study can be applied in the planning and management of current and future ANM schemes where major considerations are encouraged to be given to generator location, size, network topology and architecture when awarding non-firm contracts.

\section{Acknowledgements}

This work has been funded by the UK's Engineering and Physical Science Research Council (EPSRC), project reference number EP/G037728/1.

\section{References}

[1] Energy Networks Association, "Active Network Management Good Practice Guide," 2015.

[2] R. Passey, T. Spooner, I. MacGill, M. Watt, and K. Syngellakis, "The potential impacts of grid-connected distributed generation and how to address them: A review of technical and non-technical factors," Energy Policy, vol. 39, 2011.

[3] K. L. Anaya and M. G. Pollitt, "Experience with smarter commercial arrangements for distributed wind generation," Energy Policy, vol. 71, pp. 52-62, 2014.

[4] G. Strbac, N. Jenkins, M. Hird, P. Djapic, and G. Nicholson, "Integration of operation of embedded generation and distribution networks," May,2002.
[5] M. J. Dolan, E. M. Davidson, I. Kockar, G. W. Ault, and S. D. J. McArthur, "Distribution power flow management utilizing an online optimal power flow technique," Power Syst. IEEE Trans., vol. 27, no. 2, pp. 790-799, 2012.

[6] R. A. F. Currie, G. W. Ault, C. E. T. Foote, N. M. McNeill, and a. K. Gooding, "Smarter ways to provid grid connections for renewable generators," IEEE PES Gen. Meet. PES 2010, pp. 1-6, 2010.

[7] L. Kane and G. Ault, "A review and analysis of renewable energy curtailment schemes and principles of access: Transitioning towards business as usual," Energy Policy, vol. 72, pp. 67-77, 2014.

[8] W. Sun and G.P. Harrison, "Influence of generator curtailment priority on network hosting capacity," no. 1453, pp. 10-13, 2013.

[9] Scottish and Southern Energy Power Distribution, "Smart grid strategic review: The Orkney islands active network management scheme," no. September 2011, pp. $1-25,2012$.

[10] M. J. Currie R.A.F, Ault G.W, Foote C.E, "Active power-flow management utilising operating margins for the increased connection of distributed generation," Gener. Transm. Distrib. IET, vol. 1, no. 2, p. 324, 2007.

[11] M. J. Dolan, "Using optimal power flow for management of power flows in active distribution networks within thermal constraints," 2009.

[12] K. L. Anaya and M. G. Pollitt, "Finding the optimal approach for allocating and realising distribution system capacity: Deciding between interruptible connections and firm DG connections," no. October 2013.

[13] J. D. Robert Currie, Bryan O'Neill, Colin Foote, Alan Gooding, Robert Ferries, "Commercial arrangements to facilitate active network management," no. 1186, pp. 69, 2011.

[14] ESB National Grid, "Options for operating rules to curtail wind generation," vol. Vesion 1.0, no. CER/04/247, 2004.

[15] Baringa Partners and UK Power Networks, "Flexible plug and play principles of access report," no. December, p. $120,2012$.

[16] European Commission. "European Smart Grids Technology Platform : Vision and strategy for Europe's electricity networks of the future", vol. 19, no. 3. 2006.

[17] S. C. E. Jupe and P. C. Taylor, "Distributed generation output control for network power flow management," IET Renew. Power Gener., vol. 3, no. August 2008, p. 371, 2009.

[18] T. Boehme, G. P. Harrison, and A. R. Wallace, "Assessment of distribution network limits for non-firm connection of renewable generation," IET Renew. Power Gener., vol. 4, no. 1, p. 64, 2010.

[19] J. Carpentier, "Optimal power flows," Int. J. Electr. Power Energy Syst., vol. 1, no. 1, pp. 3-15, 1979.

[20] H. Dommel and W. Tinney, "Optimal power flow solutions," IEEE Trans. Power Appar. Syst., vol. PAS87, no. 10, pp. 1866-1876, 1968.

[21] R D. Zimmerman and C. E. Murillo "Matpower: A Matlab power system simulation package" 2014. 